\title{
TNFAIP2 Inhibits Early TNFa-Induced NF-kB Signaling and Decreases Survival in Septic Shock Patients
}

\author{
Simone A. Thair ${ }^{a, c}$ Elena Topchiy ${ }^{c}$ John H. Boyd ${ }^{c}$ Mihai Cirstea ${ }^{c}$ \\ Catherine Wang ${ }^{c}$ Taka-aki Nakadad Christopher D. Fjell ${ }^{c}$ Mark Wurfel ${ }^{b}$ \\ James A. Russell ${ }^{c}$ Keith R. Walley ${ }^{c}$

 \\ Pulmonary and Critical Care Medicine, University of Washington, Harborview Medical Center, Seattle, Wash., USA; \\ 'Centre for Heart Lung Innovation, St. Paul's Hospital, University of British Columbia, Vancouver, B.C., Canada; \\ ${ }^{\mathrm{d}}$ Department of Emergency and Critical Care Medicine, Chiba University Graduate School of Medicine, Chiba, Japan
}

\section{Key Words}

Cytokines $\cdot$ Immune response $\cdot$ Sepsis $\cdot$ Septic shock $\cdot$ Tumor necrosis factor $a \cdot$ TNFAIP2 $\cdot$ Nuclear factor-KB $\cdot$ Interleukin-8

\begin{abstract}
During septic shock, tumor necrosis factor alpha (TNFa) is an early response gene and induces a plethora of genes and signaling pathways. To identify robust signals in genes reliably upregulated by TNFa, we first measured microarray gene expression in vitro and searched methodologically comparable, publicly available data sets to identify concordant signals. Using tag single-nucleotide polymorphisms in the genes common to all data sets, we identified a genetic variant of the TNFAIP2 gene, rs8126, associated with decreased 28-day survival and increased organ dysfunction in an adult cohort in the Vasopressin and Septic Shock Trial. Similar to this cohort, we found that an association with rs8126 and increased organ dysfunction is replicated in a second cohort of septic shock patients in the St. Paul's Hospital Intensive Care Unit. We found that TNFAIP2 inhibits NF$\mathrm{KB}$ activity, impacting the downstream cytokine interleukin
\end{abstract}

\section{KARGER}

(c) 2015 S. Karger AG, Basel

$1662-811 \mathrm{X} / 15 / 0081-0057 \$ 39.50 / 0$

E-Mail karger@karger.com

www.karger.com/jin
(IL)-8. The minor G allele of TNFAIP2 rs8126 resulted in greater TNFAIP2 expression, decreased IL-8 production and was associated with decreased survival in patients experiencing septic shock. These data suggest that TNFAIP2 is a novel inhibitor of NF-KB that acts as an autoinhibitor of the TNFa response during septic shock.

(c) 2015 S. Karger AG, Basel

\section{Introduction}

Tumor necrosis factor alpha (TNFa) is involved in the early inflammatory response of septic shock and induces a plethora of genes via numerous intracellular signaling pathways. Numerous clinical trials have effectively neutralized TNFa in patients with severe sepsis without improving outcome [1-5]. Conversely, in large numbers of patients on chronic anti-TNFa therapy for inflammatory conditions, it has become evident that a properly functioning TNF $\alpha$ pathway is essential to mount an effective

\section{S.A.T. and E.T. contributed equally to this publication.}

Dr. Keith R. Walley

Centre for Heart Lung Innovation 1081 Burrard Street

Vancouver, BC V6Z 1Y6 (Canada)

E-Mail Keith.Walley@hli.ubc.ca 
antimicrobial response [6]. We reasoned that genes that are highly upregulated early in the TNF $\alpha$ response may play a clinically important role. We further reasoned that if these genes had clinically important effects, then genetic variants of these genes may be associated with differences in clinical outcome in septic shock. To identify robust signals in genes reliably induced by TNFa, we first measured microarray gene expression and searched methodologically comparable, publicly available data sets to identify concordant signals. Next, in genes reliably induced by $\mathrm{TNFa}$, we genotyped single-nucleotide polymorphisms (SNPs) that tagged groups of SNPs in linkage disequilibrium within genes highly regulated by $\mathrm{TNF} \alpha$. We tested for an association between these tagSNPs and 28-day survival in a cohort of septic shock patients in the Vasopressin and Septic Shock Trial (VASST). This approach identified a gene, TNFAIP2, and a genetic variant, rs8126, which allowed us to gain insight into the potential mechanism of its modulatory effect. Specifically, we found that TNFAIP2 inhibits NF- $\kappa B$ activity, impacting downstream cytokines such as interleukin (IL)-8. The minor $\mathrm{G}$ allele of TNFAIP2 $\mathrm{rs} 8126$ resulted in greater TNFAIP2 expression, decreased NF- $\mathrm{KB}$ activity and IL-8 production and was associated with increased mortality and renal dysfunction in patients experiencing septic shock. We found a concordant association with rs 8126 and renal dysfunction in a second independent cohort of septic shock patients. These data suggest that TNFAIP2 is a novel inhibitor of NF- $\mathrm{\kappa B}$ that may act to modulate the inflammatory response in septic shock.

\section{Methods}

\section{Gene Expression Microarray Measurements}

TNFa Induction

HeLa cells were cultured in DMEM with $10 \%$ FBS, and treated with or without $10 \mathrm{ng} / \mathrm{ml} \mathrm{TNFa}$ for $4 \mathrm{~h}$, in biological quadruplicate. RNA was harvested and gene expression was interrogated using the Illumina human HT-12 (v4) expression BeadChip (Genome Quebec Innovation Centre, Montreal, Que., Canada). Data were normalized and fold change was calculated using FlexArray v1.4.1. MIAME compliant data from the HT-12 Illumina gene expression microarray is available at GEO. We then performed a literature search to test for the replication of our results in publically available data sets by using the following criteria in the PubMed search engine: TNF, HELA, MICROARRAY and HUMAN. This resulted in a list of 12 publications (online suppl. table 1; see www. karger.com/doi/10.1159/000437330 for all online suppl. material). Each publication's methods were individually inspected and then selected if they met the following criteria: if the cell type was HeLa, stimulation was with human recombinant TNFa, the stimulation time was $3-5 \mathrm{~h}$ and the data files were not encrypted when downloaded from GEO. The search identified 2 publications $[7,8]$. Once the data sets were obtained, lists of genes were filtered for genes upregulated compared to controls, as the scope of this study is for highly upregulated genes. We then filtered the lists to include only genes with a fold change $>2$. An Excel INDEX/MATCH formula was executed to determine which genes were present in all 3 data sets. To confirm the findings, the lists (online suppl. table 2) were then loaded into: http://bioinformatics.psb.ugent.be/cgi-bin/liste/ Venn/calculate_venn.htpl. Overlap between data sets generated a Venn diagram (online suppl. fig. 1) and lists of genes represented in each section of the Venn diagram can be found in online supplementary table 3. Genes common to all 3 lists were then selected for genotyping in a large cohort of septic shock patients.

TNFAIP2 siRNA or Overexpression of rs8126 A or G Clones Followed by TNFa Stimulation

TNFAIP2 siRNA (Stealth siRNA Technology, Invitrogen/Life Technologies) was transfected using Lipofectamine 2000 as per the manufacturer's instructions. TNFAIP2 knockdown was verified using qRT-PCR. Forty-eight hours after siRNA, there was a $97.8 \%$ knockdown of TNFAIP2. HeLa cells were cultured in DMEM with $10 \% \mathrm{FBS}$ and were treated with or without $10 \mathrm{ng} / \mathrm{ml} \mathrm{TNFa} \mathrm{for} \mathrm{the}$ last $4 \mathrm{~h}$ of $48 \mathrm{~h}$ of transfection, as TNFAIP2 is not constitutively transcribed $[9,10]$ (in biological quadruplicate). For overexpression, HeLa cells were cultured as above and were transfected with TNFAIP2 overexpression plasmids containing either the A or G allele of TNFAIP2 rs8126 for $48 \mathrm{~h}$ (Origene custom plasmids CW100407 and CW101532, Origene). Array analysis was as described above.

\section{Quantitative Real-Time PCR}

Quantitative real-time (qRT)-PCR was used to validate TNFAIP2 gene expression in HeLa cells stimulated with or without $10 \mathrm{ng} / \mathrm{ml} \mathrm{TNF}$ a for $4 \mathrm{~h}(\mathrm{n}=4)$ using the QuantiTect SYBR green PCR kit, and data were collected on the ViiA 7 real-time PCR system. Primer sequences were as follows: TNFAIP2 forward $5^{\prime}$ CCCCAATGACATCATCAACA $3^{\prime}$ and reverse $5^{\prime}$ GCCTCACTGGACAGGAATGT3'; GAPDH forward 5'TGCACCACCAACTGCTTAGC3' and reverse 5'GGCATGGACTGTGGTCATGA3'.

\section{Patient Cohorts}

Vasopression and Septic Shock Trial (VASST) Cohort

(Discovery Cohort)

VASST was a multicenter, randomized, double-blind, controlled trial evaluating the efficacy of vasopressin versus norepinephrine in 779 patients who were diagnosed with septic shock according to the current consensus definition [11]. Clinical phenotyping has been described previously [12]. All patients were enrolled within $24 \mathrm{~h}$ of meeting the definition of septic shock. DNA was extracted from peripheral blood samples using a QIAamp DNA blood midi kit (QIAgen, Mississauga, Ont., Canada) from 632 patients. Written informed consent was obtained from all patients or their authorized representatives and the trial was approved by all ethics boards of the participating institutions. The research ethics board at the coordinating center (University of British Columbia) approved the genetic analysis.

St. Paul's Hospital Intensive Care Unit (SPHICU) Cohort (Replication Cohort)

All patients admitted to the SPHICU, Vancouver, B.C., Canada, between July 2000 and January 2004 underwent screening.
Thair/Topchiy/Boyd/Cirstea/Wang/ Nakada/Fjell/Wurfel/Russell/Walley 
Two hundred and fourteen Caucasian patients presenting with septic shock upon admission and for whom phenotypic data were available were selected for SNP genotyping. This study was approved by the Institutional Review Board at SPH and the University of British Columbia.

\section{SNP Genotyping}

TagSNPs in genes identified in the above microarray studies were selected using a linkage disequilibrium-based method (LDselect [13]) using an $\mathrm{r}^{2}$ threshold of 0.65 for SNPs with a minor allele frequency of $>5 \%$. These tagSNPs were genotyped in all patients of the VASST cohort with available DNA. DNA was extracted from peripheral blood samples using a QIAamp DNA blood midi kit (QIAgen) and genotyped using the Illumina Golden Gate assay (UBC Centre for Molecular Medicine). We then collected dense genotyping of 68 SNPs in the region $+/-50,000$ bp of TNFAIP2 in 530 Caucasian VASST patients from the Human Illumina Duo 1.2M SNP chip v3 (Therapeutics Genotyping Core Facility, Toronto, Ont., Canada) [14].

In the SPHICU replication cohort, rs8126 was SNP genotyped in 214 Caucasian patients using a custom Illumina Infinium iSelect BeadChip assay at the Children's Hospital of Philadelphia Research Institute/Center for Applied Genomics.

\section{Quality Control for Genotyping Data}

Sample data from Illumina GenomeStudio were imported into Golden Helix SVS software v7.6.4. Genotype data generated with the HapCluster algorithm were selected for analysis [15]. Quality control methods for call rate, cryptic relatedness, gender verification and population structure can be found in Supplemental Methods; these were all performed in SVS unless indicated otherwise.

\section{TNFAIP2 Protein Levels}

HeLa cells were cultured in DMEM with 10\% FBS and were transfected with TNFAIP2 overexpression plasmids containing either the A or G allele of TNFAIP2 rs8126 for $48 \mathrm{~h}$ (Origene custom plasmids CW100407 and CW101532, Origene). Protein levels of TNFAIP2 were assayed by Western blot ( 5 biological replicates). TNFAIP2 levels were normalized to $\beta$-actin as a loading control, and densitometry was calculated using Image J v1.46r.

\section{$N F-\kappa B$ Luciferase Assay}

HeLa cells were cultured as above. The cells were co-transfected with $0.7 \mu \mathrm{g}$ pNF- $\kappa \mathrm{B}$ luciferase reporter construct (pNFkB-Luc, Clontech) with $0.2 \mu \mathrm{g}$ of the renilla control plasmid (pRL-TK, Promega) as well as $0.5 \mu \mathrm{g}$ of one of the following constructs: TNFAIP2 rs8126 A allele, TNFAIP2 G allele or control plasmid (Origene) for a total of $1.4 \mu \mathrm{g}$ of DNA per 400,000 cells. The pNFkB-Luc is designed with 4 tandem repeats of the NF- $\kappa B$ consensus sequence followed by a TATA-like promoter ( $\mathrm{pTAL}$ ) from the herpes simplex virus thymidine kinase promoter followed by the firefly luciferase gene. Luciferase activity was measured according to the manufacturer's protocol using the Dual Glo luciferase assay (Promega) in biological triplicate.

For co-transfection of TNFAIP2 siRNA (Stealth siRNA technology, Invitrogen/Life Technologies) and NF- $\mathrm{B}$ luciferase, the luciferase construct was prepared as above, and included the co-transfection of siRNA for a final concentration of $25 \mathrm{nM}$. Transfection was performed in biological quadruplicate using Lipo- fectamine 2000 for $48 \mathrm{~h}$ and treated for the last $24 \mathrm{~h}$ with $10 \mathrm{ng} / \mu \mathrm{l}$ of TNFa in order to induce endogenous TNFAIP2. The luciferase assay of all 4 biological replicates included technical duplicates.

\section{IL-8 ELISA}

HeLa cells were cultured and transfected as above with TNFAIP2 siRNA or overexpression vectors using Lipofectamine 2000 for $48 \mathrm{~h}$ in biological triplicate. Stimulation with $10 \mathrm{ng} / \mu \mathrm{l}$ of TNFa was then added for the last $24 \mathrm{~h}$ prior to the collection of supernatant in the siRNA experiments, and for the last $4 \mathrm{~h}$ in the overexpression experiments.

IL-8 ELISAs were conducted according to the manufacturer's protocol (R\&D Systems, Minneapolis, Minn., USA).

\section{Statistical Analysis}

We used the Kaplan-Meier log-rank test to test for an association between tagSNPs and septic shock survival. The Nyholt correction was applied for multiple tests. In order to prevent spurious associations due to population stratification, all subsequent analysis was limited to Caucasian patients. We then used the Armitage trend test to test for association of the 68 SNPs in TNFAIP2 with 28 -day survival of septic shock. We used the Cox regression analysis in the VASST cohort to correct for potentially confounding variables including age, gender, ancestry, and surgical versus medical diagnostic category. We used a log-rank test to test an rs8126 additive model in the VASST cohort. We then tested for an association between the secondary outcome measures of the days alive and free of organ failure using the Kruskal-Wallis test. We assessed baseline characteristics using the $\chi^{2}$ test for categorical data and the Kruskal-Wallis test for continuous data, and then reported the median and interquartile ranges. We used the Student t test for comparison between alleles in vitro. Analyses used SPSS v16 (SPSS, Chicago, Ill., USA), the R statistical software package and GraphPad Prism v5.02 (GraphPad, La Jolla, Calif., USA).

\section{Results}

\section{TNFAIP2 Discovery Using Microarrays and TagSNP Genotyping}

To identify transcripts that are highly expressed and hence represent key genes in the response to TNFa, microarray gene expression analysis was performed on mRNA collected from HeLa cells stimulated with TNFa compared to controls, and then cross-referenced with publically available data sets (online suppl. tables 1,2 ). Three genes with a fold change $>2$ were common to all lists: TNFAIP2 (B94), NFKBIA (I $\kappa \alpha \alpha)$ and NFKB1 ( $p 105)$ (online suppl. fig. 1; online suppl. table 3 ). We therefore genotyped 13 tagSNPs in the 3 genes in the VASST cohort of septic shock patients. Of these tagSNPs, rs8176373 in the TNFAIP2 gene was significantly associated with survival in the VASST cohort $(\mathrm{n}=616, \mathrm{p}=0.0019$, Nyholt correction $\mathrm{p}=0.018$; table 1$)$. qRT-PCR confirmed TNFAIP2 expression levels (online suppl. fig. 2). 
Fig. 1. Armitage trend test of 68 SNPs +/$50,000 \mathrm{bp}$ of TNFAIP2. Of the 68 SNPs interrogated, rs8126 was the most significantly associated with 28-day survival in 519 patients in the VASST cohort $(\mathrm{p}=$ 0.007 , Caucasians only). $\operatorname{rs} 8176373$ ( $\mathrm{p}=$ 0.02 ) is the original discovery tagSNP.

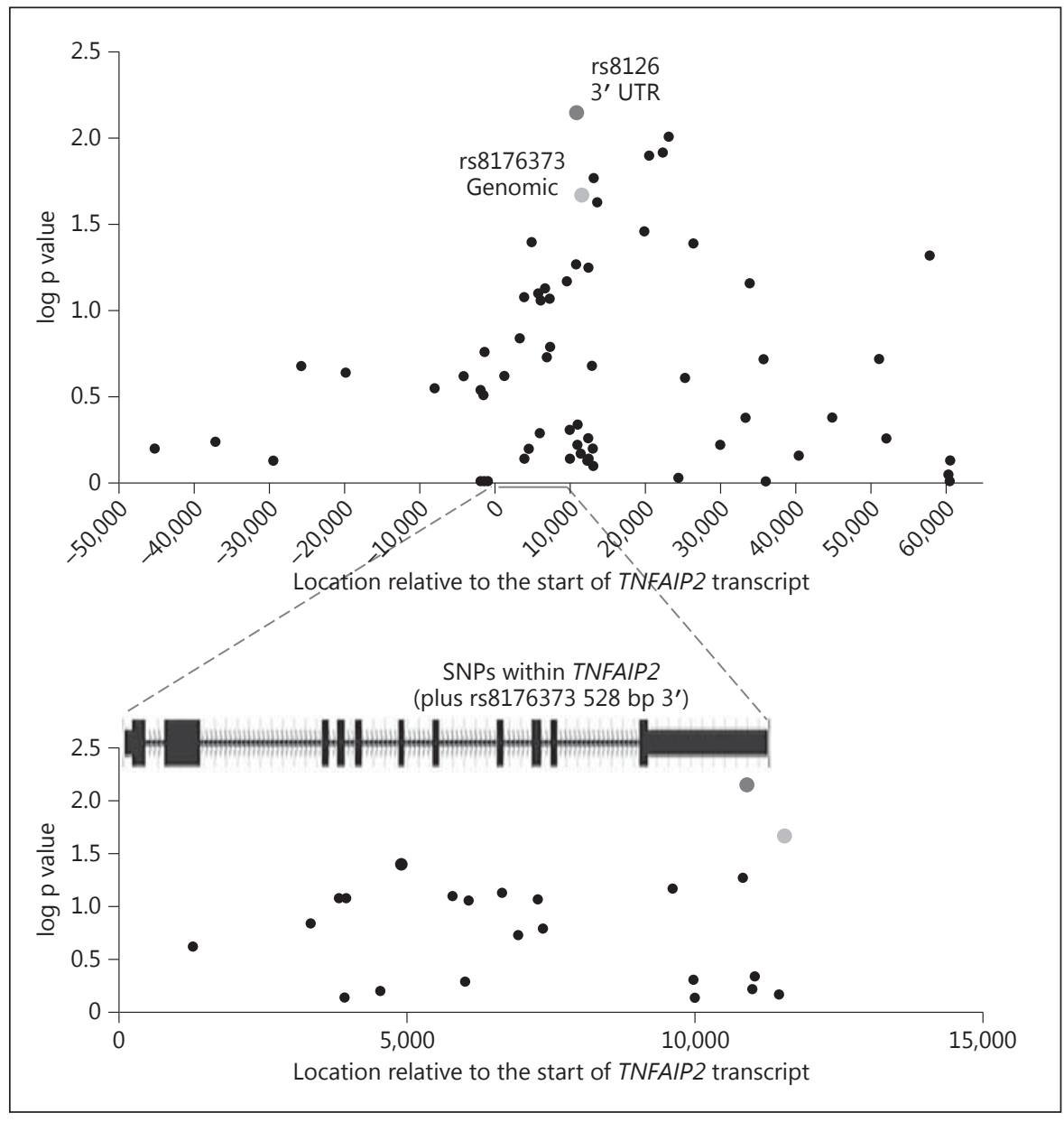

Table 1. log-rank analysis of 13 tagSNPs in 3 genes found by microarray



HWE = Hardy-Weinberg equilibrium .

60
Thair/Topchiy/Boyd/Cirstea/Wang/ Nakada/Fjell/Wurfel/Russell/Walley 




Fig. 2. Kaplan-Meier survival curves for Caucasian patients with septic shock in the VASST cohort by TNFAIP2 rs8126. Visual inspection suggests a major allele model, where carriage of at least 1 copy of the $G$ allele is detrimental. All subsequent analysis was performed using this model $(\mathrm{n}=519, \mathrm{p}=0.0043)$.

\section{Dense Genotyping Identifies rs 8126}

In order to elucidate the source of the tagSNP signal, we densely genotyped $+/-50,000$ bp upstream and downstream of TNFAIP2. Of the 68 SNPs interrogated in the region by the Armitage trend test, rs 8126 was the most significantly associated with 28-day survival in 519 Caucasian patients in the VASST cohort $(\mathrm{p}=0.007$; fig. 1$)$. rs8126 SNP is located within $3^{\prime}$-untranslated region (UTR) of TNFAIP2, a region known for its involvement in the regulation of translation and miRNA binding [16].

\section{Septic Shock Patients with the rs8126 G Allele Have \\ Increased Mortality and Organ Failure \\ VASST Cohort}

Patients of the AA genotype of TNFAIP2 rs8126 had significantly increased 28-day survival compared to patients with the GG genotype (log-rank, $\mathrm{p}=0.0043$; fig. 2). Visual inspection of the Kaplan-Meier curves suggests a major allele model, whereby carriage of $\geq 1$ copies of the $G$ allele is detrimental, so patients carrying 2 copies of the A (major) allele were grouped and compared to all patients carrying 1 or 2 copies of the G (minor) allele. Henceforth, we compared patients with an AA genotype to those with GG and AG genotypes.

To test for potentially confounding variables such as age, gender and surgical diagnosis, we performed the Cox
Table 2. 28-day mortality hazard ratios in 519 VASST Caucasian patients with septic shock

\begin{tabular}{lll}
\hline & VASST cohort & p value \\
\hline Age & $1.019(1.008-1.030)$ & $2.0 \times 10^{-4}$ \\
Female & $1.030(0.760-1.391)$ & 0.85 \\
Surgical diagnosis & $0.853(0.584-1.213)$ & 0.38 \\
TNFAIP2 rs8126 G allele & $1.460(1.083-1.961)$ & 0.013 \\
\hline
\end{tabular}

Values are shown as a hazard ratio (confidence interval). Cox regression analysis was performed to correct for age, gender and surgical versus medical diagnosis using a major allele model.

regression and found that patients who had the GG/AG genotype of TNFAIP2 rs8126 had significantly decreased survival compared to those with the AA genotype [hazard ratio of death for GG/AG vs. AA genotype: $1.46 ; 95 \%$ confidence interval 1.08-1.96; $\mathrm{p}=0.013$ (Caucasians only); table 2]. There were no significant differences in the baseline characteristics of the VASST cohort patients when comparing the AA and GG/AG genotypes (table 3). The rs8126 GG/AG genotype patients also experienced significantly fewer days alive and free (therefore more organ dysfunction and a worse outcome) of respiratory ( $\mathrm{p}=$ $0.008)$ and renal failure $(p=0.001)$ as well as renal replacement therapy $(\mathrm{p}=0.021)$ than the AA genotype patients (table 4). These data suggest that the G allele may be detrimental; the patients carrying 1 or 2 of these alleles have more organ dysfunction and increased mortality.

\section{SPHICU Cohort}

The most significant findings in the VASST cohort were the statistically significant differences in renal dysfunction and the need for renal replacement therapy across genotypes. We therefore tested for replication of this observation in a second cohort of septic shock patients. Similar to the VASST cohort, SPHICU patients with the TNFAIP2 rs8126 GG/AG genotypes had fewer days alive and free from renal failure (therefore more organ dysfunction and a worse outcome; $\mathrm{p}=0.031$ ) and renal replacement therapy (trend: $p=0.071$; table 5 ). There were no differences between genotypes in the baseline prevalence of chronic renal failure [26\% (AA) vs. $37 \%$ (GG/AG); $\mathrm{p}=0.99$ ] and baseline creatinine $\mu \mathrm{mol} / \mathrm{l}$ [median and interquartile range: AA 160 (88-266) vs. GG/ GA 141 (84-235); $\mathrm{p}=0.42$ ]. The survival of AA patients (54.0\%) was higher than that of AG/GG patients (47.7\%), but this difference was not statistically significant in this smaller replication cohort. 
Table 3. Baseline characteristics of VASST Caucasian septic shock patients by TNFAIP 2 rs 8126 genotype

\begin{tabular}{|c|c|c|c|}
\hline & $\begin{array}{l}\mathrm{AA} \\
(\mathrm{n}=330)\end{array}$ & $\begin{array}{l}\text { GG/AG } \\
(n=189)\end{array}$ & $\mathrm{p}$ value \\
\hline Age, years & $64(50-74)$ & $63(53-72)$ & 0.42 \\
\hline Male gender, $\%$ & 61.9 & 62.4 & 0.23 \\
\hline APACHE II & $26(21-32)$ & $27(22-32)$ & 0.38 \\
\hline Surgery, \% & 21.2 & 22.8 & 0.50 \\
\hline \multicolumn{4}{|l|}{ Pre-existing conditions, $\%$} \\
\hline Chronic heart failure & 7.0 & 10.6 & 0.37 \\
\hline Chronic pulmonary disease & 17.0 & 18.5 & 0.66 \\
\hline Chronic liver disease & 11.2 & 9.5 & 0.82 \\
\hline Chronic renal failure & 10.9 & 9.5 & 0.27 \\
\hline Chronic corticosteroid use & 20.3 & 20.6 & 0.86 \\
\hline \multicolumn{4}{|l|}{ Cardiovascular variables on day 1} \\
\hline Heart rate, bpm & $128(112-141)$ & $125(108-135)$ & 0.094 \\
\hline Mean arterial pressure, $\mathrm{mm} \mathrm{Hg}$ & $56(50-62)$ & $55(49-61)$ & 0.53 \\
\hline Central venous pressure, $\mathrm{mm} \mathrm{Hg}$ & $14(11-17)$ & $15(12-18)$ & 0.20 \\
\hline \multicolumn{4}{|l|}{ Laboratory variables on day 1} \\
\hline White blood cell count, $10^{3} / \mathrm{mm}^{3}$ & $13.7(7.4-20.5)$ & $14.1(8.4-22.4)$ & 0.36 \\
\hline Platelet count, $10^{3} / \mathrm{mm}^{3}$ & $152(87-242)$ & $179(96-272)$ & 0.31 \\
\hline $\mathrm{PaO}_{2} / \mathrm{FiO}_{2}, \mathrm{~mm} \mathrm{Hg}$ & $197(143-256)$ & $182(136-246)$ & 0.17 \\
\hline Creatinine, $\mu \mathrm{mol} / \mathrm{l}$ & $141(89-248)$ & $170(93-262)$ & 0.27 \\
\hline Lactate, $\mathrm{mmol} / \mathrm{l}$ & $1.7(0.8-3.3)$ & $1.9(1.1-3.8)$ & 0.25 \\
\hline \multicolumn{4}{|l|}{ Microbiological results, n (\%) } \\
\hline Culture positive for Gram-negative organism & $75(22.7)$ & $39(20.6)$ & 0.66 \\
\hline Culture positive for Gram-positive organism & $101(30.6)$ & $58(30.7)$ & 1.00 \\
\hline Culture positive for any primary site & $183(55.5)$ & $105(55.6)$ & 0.93 \\
\hline
\end{tabular}

Values are reported as median (IQR) unless otherwise specified. APACHE II = Acute Physiology and Chronic Health Evaluation II.

Table 4. Days alive and free of organ dysfunction and artificial support in VASST Caucasian septic shock patients by TNFAIP2 rs8126 genotype

\begin{tabular}{lrrl}
\hline Parameter & $\begin{array}{l}\text { AA } \\
(\mathrm{n}=330)\end{array}$ & $\begin{array}{l}\text { GG/AG } \\
(\mathrm{n}=189)\end{array}$ & $\begin{array}{l}\mathrm{p} \\
\text { value }\end{array}$ \\
\hline $\begin{array}{l}\text { Organ dysfunction } \\
\quad \text { Cardiovascular }\end{array}$ & $20(0-24)$ & $13(0-24)$ & 0.06 \\
$\quad$ Respiratory & $4(0-16)$ & $2(0-14)$ & 0.008 \\
$\quad$ Renal & $24(7-28)$ & $13(1-28)$ & 0.001 \\
$\quad$ Hematologic & $25(8-28)$ & $24(3-28)$ & 0.39 \\
$\quad$ Hepatic & $27(8-28)$ & $23(3-28)$ & 0.06 \\
$\quad$ Neurologic & $17(0-25)$ & $14(0-23)$ & 0.07 \\
Artificial organ support & & & \\
$\quad$ Vasopressor & $20(0-24)$ & $16(0-24)$ & 0.07 \\
$\quad$ Ventilator & $10(0-22)$ & $6(0-19)$ & 0.08 \\
$\quad$ Renal replacement therapy & $28(9-28)$ & $20(4-28)$ & 0.021 \\
\hline
\end{tabular}

Data are reported as median (IQR).
Table 5. Days alive and free from organ dysfunction and artificial support in SPHICU Caucasian septic shock patients by TNFAIP2 rs8126 genotype

\begin{tabular}{llll}
\hline Parameter & $\begin{array}{l}\text { AA } \\
(\mathrm{n}=126)\end{array}$ & $\begin{array}{l}\text { GG/AG } \\
(\mathrm{n}=88)\end{array}$ & $\begin{array}{l}\mathrm{p} \\
\text { value }\end{array}$ \\
\hline $\begin{array}{l}\text { Organ dysfunction } \\
\quad \text { Renal }\end{array}$ & $15(3-28)$ & $9(1-24)$ & 0.031 \\
$\begin{array}{l}\text { Artificial organ support } \\
\quad \text { Renal replacement therapy }\end{array}$ & $20(4-28)$ & $11(1-28)$ & 0.071 \\
\hline
\end{tabular}

Data are reported as median (IQR).

\section{TNFAIP2 Protein Expression Is Significantly Higher} with the rs 8126 G Allele

To determine the functionality of rs8126 with regard to the regulation of TNFAIP2 expression and the subsequent protein expression, clones of the TNFAIP2 overexpression vector expressing either the $A$ or $G$ allele of 




Fig. 3. TNFAIP2 levels are associated with TNFAIP2 rs8126 genotypes. Overexpression of TNFAIP2 clones representing the rs 8126 A and rs8126 G alleles in HeLa cells. Protein levels of TNFAIP2 are 1.6-fold greater for the rs $8126 \mathrm{G}$ allele (TNFAIP2/ $\beta$-actin ratio: $1.1)$ than for the A allele $(\mathrm{n}=5$; TNFAIP $2 / \beta$-actin ratio: 0.7$) .{ }^{*} \mathrm{p}=$ 0.045 . A representative image of TNFAIP 2 and $\beta$-actin Western blots is included.



Fig. 4. TNFAIP2 inhibits basal NF- $\kappa B$ luciferase activity with a more pronounced effect in the rs $8126 \mathrm{G}$ allele. When co-transfected with the A allele, NF- $\kappa B$ activity is reduced to $22 \%$ compared to the control vector $\left.\left(\mathrm{p}_{(\mathrm{A} \text { to control }}\right)=0.01\right)$, is even further reduced to $10 \%$ when the $\mathrm{G}$ allele is expressed $\left(\mathrm{p}_{(\mathrm{G} \text { to control })}=0.009\right)$ and there is a statistically significant difference between the 2 alleles $(n=3)$. ${ }^{*} \mathrm{p}_{(\mathrm{A} \text { to } \mathrm{G})}=0.013$.

TNFAIP2 rs8126 were transfected into HeLa cells for $48 \mathrm{~h}$, and cell lysates were then assayed by Western blot for TNFAIP2. We found that the ratio of the G allele to $\beta$-actin was 1.1 whereas the A allele had a ratio of 0.7 and a fold difference of 1.6 , suggesting that TNFAIP2 levels are higher when the $\mathrm{G}$ allele (minor) is present (5 biological replicates; $\mathrm{p}=0.045$; fig. 3 ).

Similar results were obtained after TNFa stimulation (online suppl. fig. 3).

\section{TNFAIP2 Inhibits Basal NF- $\kappa B$ Activity in}

Unstimulated Cells in an Allele-Specific Manner

In light of the allele-specific differences that we observed for TNFAIP2 protein levels, we co-transfected HeLa cells with either the rs8126 A or G allele of TNFAIP2, along with the NF- $\kappa B$ luciferase reporter to observe NF- $\kappa$ B activity. Both alleles of TNFAIP2 significantly inhibited NF- $\kappa B$ compared to the control; the A allele inhibited NF- $\kappa \mathrm{B}$ activity to $22 \%$ ( $\mathrm{p}_{\text {(A to control) }}=0.01$ ) and the $\mathrm{G}$ allele inhibited NF- $\kappa \mathrm{B}$ activity to $10 \%\left(\mathrm{p}_{(\mathrm{G} \text { to control })}=0.009\right)$ and there was a significant difference between the 2 alleles ( 3 biological replicates; $\mathrm{p}_{(\mathrm{A} \text { to } \mathrm{G})}=0.013$; fig. 4$)$. This suggests that TNFAIP2 inhibits NF- $\kappa B$ signaling (the effect is more pronounced with the rs8126 G allele) and may be a part of the negative feedback loop regulation of NF- $\mathrm{kB}$ activation.

\section{TNFAIP2 Silencing in TNF $\alpha$-Stimulated Cells}

Upregulates NF- $\kappa B$ Activity, IL-8 mRNA and Protein

Co-transfection of TNFAIP2 siRNA and NF- $\kappa$ B luciferase resulted in an upregulation of NF- $\kappa B$ luciferase reporter activity ( $\mathrm{n}=4, \mathrm{p}<0.0001$; fig. 5$)$; of note, this is the opposite of the overexpression of TNFAIP 2 alleles. IL- 8 is a key cytokine in the immune response during septic shock [17], so we looked specifically at the transcription of IL-8 under TNFAIP2 siRNA conditions in HeLa cells. Based on the luciferase results, we would expect to see an upregulation of IL-8 after transfection with siRNA. We found that IL-8 gene expression was increased by a fold change of 1.925 ( $\mathrm{p}<0.0001$ ). Similarly, an ELISA of HeLa cell supernatant after siRNA of TNFAIP2 and TNF $\alpha$ stimulation resulted in a significant increase in IL- 8 protein $(\mathrm{n}=4, \mathrm{p}<$ 0.00001; fig. 6). Conversely, upon overexpression of the rs 8126 A or G allele of TNFAIP2, we observed a trend towards inhibition of IL-8 production $\left(\mathrm{p}_{\text {(A to control) }}=0.036\right.$, $\mathrm{p}_{(\mathrm{G} \text { to control })}=0.90, \mathrm{p}_{(\mathrm{A} \text { to } \mathrm{G})}=0.031$; online suppl. fig. 4$)$. Interestingly, we found that there was no difference in IL-8 mRNA gene expression $(\mathrm{FC}=1.0, \mathrm{p}=0.243)$.

\section{Discussion}

Previous work in our lab and by other study groups has shown that genetic variation within inflammatory genes is associated with outcome in sepsis and septic shock [18-26] as well as with the levels of cytokines [27]. We have shown 




Fig. 5. NF- $\kappa B$ luciferase activity after TNFAIP2 siRNA transfection. HeLa cells were co-transfected with TNFAIP2 siRNA and $\mathrm{NF}-\kappa \mathrm{B}$ luciferase reporter construct for $48 \mathrm{~h}$. The last $24 \mathrm{~h}$ included stimulation with $10 \mathrm{ng} / \mu \mathrm{l}$ of TNFa. NF- $\kappa \mathrm{B}$ activity increased after transfection with TNFAIP2 siRNA compared to the control $(\mathrm{n}=4) .{ }^{*} \mathrm{p}<0.0001$.

here that the $3^{\prime}$ UTR SNP rs8126 of TNFAIP2 may functionally regulate the expression of the TNFAIP2 gene. Specifically, the $\mathrm{G}$ allele produces increased levels of TNFAIP2 protein in vitro and is associated with higher mortality in septic shock patients. Furthermore, we have found biological plausibility for our clinical genetics association study suggesting that TNFAIP2 is a negative regulator of NF- $\kappa \mathrm{B}$ and that this effect is genetically regulated. We cross referenced our gene expression data with published data sets and found three genes with a fold change greater than 2 in HeLa cells stimulated with TNFa common to all data sets (TNFAIP2, NFKBIA and NFKB1). We hypothesized that the genes implicated in the microarray would have SNPs associated with outcome in septic shock and that these SNPs would functionally alter signaling. TagSNP genotyping of 13 tagSNPs within the 3 genes showed that rs 8176373 of TNFAIP2 was associated with 28-day survival in the VASST cohort of septic shock patients. In order to elucidate the source of the tagSNP signal, we densely genotyped $+/-50,000 \mathrm{bp}$, upstream and downstream of TNFAIP2, and performed the Armitage trend test, which identified rs8126 as the SNP most significantly associated with 28 day survival. Interestingly, rs 8176373 is in the $528 \mathrm{bp} 3^{\prime}$ of the gene, but rs 8126 is located in the $3^{\prime}$ UTR, commonly found to regulate mRNA expression and stability [16].

Based on the discovery of rs8126, we analyzed the Caucasian patients of the VASST cohort by this SNP. The Kaplan-Meier analysis showed a statistically significant difference in 28-day survival, whereby the AA genotype



Fig. 6. IL-8 ELISA after siRNA. HeLa cells were transfected with TNFAIP2 siRNA for $48 \mathrm{~h}$. The last $24 \mathrm{~h}$ included stimulation with $10 \mathrm{ng} / \mu \mathrm{l}$ of TNFa. IL-8 ELISA shows that IL-8 protein expression was increased in the supernatant after TNFAIP2 siRNA compared to control siRNA $(\mathrm{n}=4)$. Control and TNFa conditions without any siRNA are also reported. ${ }^{*} \mathrm{p}<0.000001$.

patients had increased survival. This suggests a major allele model. This model would imply that carriage of either 1 or 2 copies of the G allele are detrimental.

To test for potentially confounding variables such as age, gender and surgical diagnosis, we performed the Cox regression using a major allele model and found that patients who had the GG/AG genotype of TNFAIP2 rs8126 had a significantly decreased survival compared to the AA genotype patients. We also found that the GG/AG genotype patients had fewer days alive and free of organ dysfunction than those with the AA genotype, specifically renal dysfunction and more renal replacement therapy. Furthermore, this effect was replicated when we interrogated renal dysfunction in an independent cohort of septic shock patients (SPHICU), whereby patients with the GG/AG genotype had fewer days alive and free of renal dysfunction than those with the AA genotype. A trend towards fewer days alive and free of renal replacement therapy was also observed.

TNFAIP2, initially discovered as a TNFa-inducible gene, is regulated by NF- $\mathrm{KB}$ under most conditions, is induced by retinoic acid in acute promyelocytic leukemia and has been associated with various carcinomas $[7,9,10$, $28-31]$. Here, we showed that TNFAIP2 is a negative regulator of NF- $\kappa B$ activity and that the $r s 8126 \mathrm{G}$ allele potentiates this inhibitory effect. NF- $\mathrm{BB}$ plays a central role in regulating the transcription of mediators important in sepsis, and represents a promising therapeutic target in patients with sepsis [32]. Interestingly, another TNFa- 
inducible gene, TNFAIP3 (A20), is well known for its upregulation in response to NF- $\mathrm{KB}$ signaling for the negative regulation of the NF- $\kappa \mathrm{B}$ pathway itself. A20 deubiquitinates RIP at Lys63 and then acts as an ubiquitin ligase to target RIP for degradation $[33,34]$. Thus, similar to the known role of A20 in negative regulation of NF- $\kappa B$ signaling, the changes we observed may reflect feedback mechanisms in TNFa superfamily-induced NF- $\kappa B$ signaling. Several approaches have been used to inhibit NF$\kappa \mathrm{B}$ in various models of sepsis [32]. However, the possibility of its use as a therapeutic target is controversial. For example, it was shown that NF- $\kappa \mathrm{B}$ inhibition improves survival in endotoxin shock and in a cecal ligation and puncture model of sepsis in combination with antibiotic therapy [35], but, conversely, mice lacking the p50 subunit of NF- $\kappa \mathrm{B}$ are unable to effectively clear Listeria monocytogenes and are more susceptible to infection with Streptococcus pneumoniae [36]. Additionally, enterocytespecific NF- $\kappa \mathrm{B}$ knockout exacerbates sepsis-induced intestinal injury and worsens mortality [37]. Our findings suggest that TNFAIP2 may be one of the several regulatory mechanisms required to modulate NF- $\kappa B$ activity to meet the demands of inflammatory response.

Taken together, our data suggest that the genotype of rs8126 associated with increased mortality in sepsis influences the inhibitory regulation by TNFAIP 2 in vitro; clones carrying the $G$ allele of rs8126 make more TNFAIP2, which leads to increased inhibition of NF- $\kappa B$. We hypothesize that TNFAIP2 could be upregulated in cellular-response settings to negatively regulate the NF$\kappa \mathrm{B}$ pathway and its downstream signaling. We postulate that increased protein levels of TNFAIP2, present when the $\mathrm{G}$ allele is expressed, may lead to the excessive inhibition of NF- $\mathrm{kB}$ signaling in septic shock, creating a state of immunosuppression due to the lower transcription of cytokines or the lack of proliferation of immune cells. Overexpression of TNFAIP2 results in an inhibition of NF- $\mathrm{KB}$ and IL- 8 protein, an effect that was reversed after siRNA silencing of TNFAIP2. This supports previous data demonstrating that IL-8 transcription is upregulated by TNFa via the NF- $\kappa$ B pathway $[38,39]$.

This study has several limitations. The analyses of the VASST and SPHICU cohorts were performed post hoc, so the relation of this SNP to outcome or therapy cannot be drawn from this study alone. The discovery that there are significant differences in renal dysfunction between rs8126 genotypes was replicated in the SPHICU cohort, but the association with 28-day survival was not statistically significant. This suggests an organ-specific effect; this justifies further phenotyping and analysis. The

TNFAIP2 Inhibits TNFa-NF- $\kappa$ B Signaling in Septic Shock Patients
Kaplan-Meier curve analysis revealed a major allele model, showing there was very little difference in mortality over time for patients carrying 1 or 2 copies of the detrimental G (minor) allele compared to those carrying 2 copies of the A (major) allele.

We did not measure levels of TNFAIP2 in our septic shock cohort, but the evidence may warrant doing so in a future study. A recent publication found that patients of the CC (GG) genotype of TNFAIP2 rs8126 have an increased risk of squamous cell carcinoma of the head and neck [29]. However, Liu et al. [29] presented luciferase reporter constructs of rs 8126 where the $C(G)$ allele made less TNFAIP2, in opposition to our observations; this result could be explained by the differences in the constructs, i.e. we used the full cDNA, but they were only concerned with the $3^{\prime}$ UTR. It is interesting to note that Chen et al. [28] found that silencing TNFAIP2 reduced the migration and invasion of nasopharyngeal carcinoma HK1 cells, but that knockdown did not affect VEGF. Hence, the migration and metastasis of the carcinomas mediated by VEGF could be via a separate mechanism, suggesting that TNFAIP2 may be pleiotropic in action. Their study did not involve TNFAIP2 overexpression. In addition, a future study with these experiments, performed in HUVECs or a renal-derived cell line, could enhance the understanding of the tissue-specific action of this mechanism. In order to design a study that would have robust findings, we chose to cross-reference our data with published data before proceeding to genotyping. The low number of genes common to all lists may be due to differences in microarray platform, cell source and passage number, recombinant protein TNFa source, concentration and time period of stimulation, and a recent publication [40] found subpopulations of HeLa cells from ATCC with varying susceptibility to the cytopathic effect of coxsackievirus B3/28. The intersection of these experiments supports the notion that these are, in fact, reliably upregulated genes.

In conclusion, we discovered an association of the $\mathrm{A}$ allele of TNFAIP2 rs8126 with increased 28-day survival and organ dysfunction in septic shock patients. Similar to the known role of A20 in the negative regulation of NF- $\mathrm{kB}$ signaling, overexpression of TNFAIP2 inhibits NF- $\kappa B$-driven luciferase activity with significant differences according to rs8126 allele. The changes may reflect feedback mechanisms in TNFa superfamily-induced NF- $\mathrm{KB}$ signaling. We found that levels of TNFAIP2 protein differ by genotype and this is supported in the NF- $\kappa B$ luciferase assay of overexpression and knockdown of TNFAIP2. In agreement with these data, cytokine levels of IL- 8 are impacted, suggesting that TNFAIP2 is a novel inhibitor of NF- $\kappa B$. 


\section{References}

1 Abraham E, et al: p55 Tumor necrosis factor 13 Howie BN, et al: Efficient selection of tagging receptor fusion protein in the treatment of patients with severe sepsis and septic shock. A randomized controlled multicenter trial. Ro 45-2081 Study Group. JAMA 1997;277:15311538.

2 Abraham E, et al: Lenercept (p55 tumor necrosis factor receptor fusion protein) in severe sepsis and early septic shock: a randomized double-blind, placebo-controlled, multicenter phase III trial with 1,342 patients. Crit Care Med 2001;29:503-510.

-3 Abraham E, et al: Efficacy and safety of monoclonal antibody to human tumor necrosis factor alpha in patients with sepsis syndrome. A randomized, controlled, double-blind, multicenter clinical trial. TNF-alpha MAb Sepsis Study Group. JAMA 1995;273:934-941.

$\checkmark 4$ Cohen J, Carlet J: INTERSEPT: an international, multicenter, placebo-controlled trial of monoclonal antibody to human tumor necrosis factor-alpha in patients with sepsis. International Sepsis Trial Study Group. Crit Care Med 1996;24:1431-1440.

5 Panacek EA, et al: Efficacy and safety of the monoclonal anti-tumor necrosis factor antibody $\mathrm{F}\left(\mathrm{ab}^{\prime}\right) 2$ fragment afelimomab in patients with severe sepsis and elevated interleukin-6 levels. Crit Care Med 2004;32:2173-2182.

6 Goode S, Tierney G, Deighton C: Life-threatening intra-abdominal sepsis in patients on anti-TNF-alpha therapy. Gut 2006;55:590591.

$>7$ Tian B, et al: Identification of direct genomic targets downstream of the nuclear factor-kappaB transcription factor mediating tumor necrosis factor signaling. J Biol Chem 2005;280 17435-17448.

8 Zhou A, et al: Identification of NF-kappa Bregulated genes induced by TNFalpha utilizing expression profiling and RNA interference. Oncogene 2003;22:2054-2064.

$>9$ Wolf FW, et al: Characterization of a novel tumor necrosis factor-alpha-induced endothelial primary response gene. J Biol Chem 1992;267:1317-1326

$>10$ Wolf FW, et al: B94, a primary response gene inducible by tumor necrosis factor alpha, is expressed in developing hematopoietic tissues and the sperm acrosome. J Biol Chem 1994;269:3633-3640.

$>11$ Sibbald WJ, Vincent JL: Roundtable conference on clinical trials for the treatment of sepsis. Brussels, March 12-14, 1994. Chest 1995; 107:522-527.

12 Russell JA, et al: Vasopressin versus norepinephrine infusion in patients with septic shock. N Engl J Med 2008;358:877-887. single-nucleotide polymorphisms in multiple populations. Hum Genet 2006;120:58-68.

14 Carlson CS, et al: Selecting a maximally informative set of single-nucleotide polymorphisms for association analyses using linkage disequilibrium. Am J Hum Genet 2004;74: 106-120.

15 Waldron ER, Whittaker JC, Balding DJ: Fine mapping of disease genes via haplotype clustering. Genet Epidemiol 2006;30:170-179.

16 Bartel DP: MicroRNAs: target recognition and regulatory functions. Cell 2009;136:215233.

17 Hack CE, et al: Interleukin-8 in sepsis: relation to shock and inflammatory mediators. Infect Immun 1992;60:2835-2842.

18 Nakada TA, et al: beta2-Adrenergic receptor gene polymorphism is associated with mortality in septic shock. Am J Respir Crit Care Med 2010;181:143-149.

19 Nakada TA, et al: Association of angiotensin II type 1 receptor-associated protein gene polymorphism with increased mortality in septic shock. Crit Care Med 2011;39:16411648.

20 Nakada TA, et al: Leucyl/cystinyl aminopeptidase gene variants in septic shock. Chest 2011;139:1042-1049.

21 Russell JA, Wellman H, Walley KR: Protein C rs2069912 C allele is associated with increased mortality from severe sepsis in North Americans of East Asian ancestry. Hum Genet 2008; 123:661-663.

22 Sutherland AM, Walley KR, Russell JA: Polymorphisms in CD14, mannose-binding lectin, and Toll-like receptor-2 are associated with increased prevalence of infection in critically ill adults. Crit Care Med 2005;33:638644.

23 Toubiana J, et al: IRAK1 functional genetic variant affects severity of septic shock. Crit Care Med 2010;38:2287-2294.

24 Vasl J, et al: Functional activity of MD-2 polymorphic variant is significantly different in soluble and TLR4-bound forms: decreased endotoxin binding by G56R MD-2 and its rescue by TLR4 ectodomain. J Immunol 2008; 180:6107-6115.

25 Walley KR, Russell JA: Protein C -1641 AA is associated with decreased survival and more organ dysfunction in severe sepsis. Crit Care Med 2007;35:12-17.

26 Wurfel MM, et al: Toll-like receptor 1 polymorphisms affect innate immune responses and outcomes in sepsis. Am J Respir Crit Care Med 2008;178:710-720.

27 Thair SA, et al: A single nucleotide polymorphism in NF-kappaB inducing kinase is associated with mortality in septic shock. J Immunol 2011;186:2321-2328.
28 Chen LC, et al: A novel role for TNFAIP2: its correlation with invasion and metastasis in nasopharyngeal carcinoma. Mod Pathol 2011;24:175-184.

29 Liu Z, et al: A functional variant at the miR184 binding site in TNFAIP2 and risk of squamous cell carcinoma of the head and neck. Carcinogenesis 2011;32:166874.

30 Magder S, et al: Lipopolysaccharide and TNFalpha produce very similar changes in gene expression in human endothelial cells. J Vasc Res 2006;43:447-461.

31 Sarma V, et al: Cloning of a novel tumor necrosis factor-alpha-inducible primary response gene that is differentially expressed in development and capillary tube-like formation in vitro. J Immunol 1992;148:3302-3312.

32 Abraham E: Nuclear factor- $\mathrm{kB}$ and its role in sepsis-associated organ failure. J Infect Dis 2003;187(suppl 2):S364-S369.

33 Boone DL, et al: The ubiquitin-modifying enzyme A20 is required for termination of Tolllike receptor responses. Nat Immunol 2004;5: 1052-1060.

34 Wertz IE, et al: De-ubiquitination and ubiquitin ligase domains of A20 downregulate NF-kappaB signalling. Nature 2004;430:694699.

>35 O'Sullivan AW, Wang JH, Redmond HP: NF$\kappa \mathrm{B}$ and P38 MAPK inhibition improve survival in endotoxin shock and in a cecal ligation and puncture model of sepsis in combination with antibiotic therapy. J Surg Res 2009;152:46-53.

36 Sha WC, et al: Targeted disruption of the p50 subunit of NF- $\kappa \mathrm{B}$ leads to multifocal defects in immune responses. Cell 1995;80:321-330.

37 Dominguez JA, et al: Inhibition of IKKbeta in enterocytes exacerbates sepsis-induced intestinal injury and worsens mortality. Crit Care Med 2013;41:e275-e285.

38 Osawa Y, et al: Tumor necrosis factor alphainduced interleukin- 8 production via NF- $\mathrm{kB}$ and phosphatidylinositol 3-kinase/Akt pathways inhibits cell apoptosis in human hepatocytes. Infect Immun 2002;70:6294-6301.

39 Zhao RZ, et al: TNF- $\alpha$ induces interleukin-8 and endothelin-1 expression in human endothelial cells with different redox pathways. Biochem Biophys Res Commun 2005;327: 985-992.

40 Carson SD, Pirruccello SJ: HeLa cell heterogeneity and coxsackievirus B3 cytopathic effect: implications for inter-laboratory reproducibility of results. J Med Virol 2013; 85:677683 